\title{
Ensino de Física no contexto da Astronomia: Um estudo de colisões a partir da teoria de formação planetária
}

Teaching Physics in the context of Astronomy: A study of collisions from the planetary formation theory

Enseñanza de Física en el contexto de la Astronomía: Un estudio de las colisiones desde la teoría de la formación planetaria

Recebido: 22/10/2021 | Revisado: 30/10/2021 | Aceito: 30/11/2021 | Publicado: 11/12/2021

Nairys Costa de Freitas
ORCID: https://orcid.org/0000-0002-0799-8489
Hustituto Federal de Educação, Ciência e Tecnologia do Ceará, Brasil
E-mail: Nairys.freitas07@aluno.ifce.edu.br
Hugo Ferreira Alves
ORCID: https://orcid.org/0000-0002-4746-465X
E-mail: hugo.alves02@aluno.ifce.edu.br
Antonio de Lisboa Coutinho Júnior
Instituto Federal de Educação, Ciência e Tecnologia do Ceá, Brasil
ORCID: https://orcid.org/0000-0001-7270-7759
Instituto Federal de Educação, Ciência e Tecnologia do Ceará, Brasil
E-mail: antonio.lisboa.coutinho74@ aluno.ifce.edu.br
Mairton Cavalcante Romeu
ORCID: https://orcid.org/0000-0001-5204-9031
Instituto Federal de Educação, Ciência e Tecnologia do Ceará, Brasil
E-mail: mairtoncavalcante@ @ifce.edu.br

\section{Resumo}

O presente artigo possui caráter descritivo, tendo como objetivo analisar as potencialidades da inserção da Astronomia no Ensino de Física, envolvendo a aplicação dos conhecimentos sobre matéria e energia em uma perspectiva fenomenológica através da teoria de formação planetária. Sendo desenvolvida uma pesquisa bibliográfica fundamentada em livros, artigos, monografias, dissertações, teses e documentos que norteiam a construção do currículo de Ciências da Natureza do Ensino Médio, possibilitando uma abordagem contextualizada no processo de ensino e aprendizagem em Física. As competências específicas da área de Ciências da Natureza e suas Tecnologias presentes na Base Nacional Comum Curricular (BNCC) incentivam a prática da investigação científica e evidenciam a importância dessa abordagem no mundo contemporâneo. Outrossim, a Ciência possibilita a observação, experimentação e investigação de fenômenos presentes no cotidiano, os quais envolvem Astronomia, despertando interesse e curiosidade nos discentes, trazendo aspectos contemporâneos no ensino de mecânica clássica. Considerando que a Astronomia possui um potencial motivador para estudantes e professores, sua abordagem é importante na compreensão de conceitos, promovendo discussões substanciais, consentindo no processo de literacia científica na educação básica.

Palavras-chave: Ensino de física; Ensino de astronomia; Ensino de colisões; Formação planetária.

\begin{abstract}
This article has a descriptive character, aiming to analyze the potential of the insertion of astronomy in Physics Teaching, involving the application of knowledge about matter and energy in a phenomenological perspective through the theory of planetary formation. A bibliographical research based on books, articles, monographs, dissertations, theses and documents that guide the construction of the curriculum of Nature Sciences in High School was developed, allowing a contextualized approach in the process of teaching and learning in Physics. The specific competencies of the area of Natural Sciences and its Technologies present in the Common National Curricular Base (BNCC) encourage the practice of scientific research and highlight the importance of this approach in the contemporary world. Moreover, Science enables the observation, experimentation and investigation of phenomena present in everyday life, which involve astronomy, arousing interest and curiosity in students, bringing contemporary aspects in the teaching of classical mechanics. Considering that astronomy has a motivating potential for students and teachers, its approach is important in understanding concepts, promoting substantial discussions, consenting in the process of scientific literacy in basic education.
\end{abstract}

Keywords: Teaching physics; Teaching astronomy; Teaching collisions; Planetary formation. 


\section{Resumen}

Este artículo tiene un carácter descriptivo, con el objetivo de analizar el potencial de la inserción de la astronomía en la Enseñanza de la Física, implicando la aplicación de los conocimientos sobre la materia y la energía en una perspectiva fenomenológica a través de la teoría de la formación planetaria. Se desarrolló una investigación bibliográfica basada en libros, artículos, monografías, disertaciones, tesis y documentos que orientan la construcción del currículo de Ciencias de la Naturaleza en la Enseñanza Media, permitiendo un abordaje contextualizado en el proceso de enseñanza y aprendizaje de la Física. Las competencias específicas del área de Ciencias Naturales y sus Tecnologías presentes en la Base Curricular Nacional Común (BNCC) fomentan la práctica de la investigación científica y destacan la importancia de este enfoque en el mundo contemporáneo. Además, la Ciencia permite la observación, experimentación e investigación de fenómenos presentes en la vida cotidiana, que implican a la Astronomía, despertando el interés y la curiosidad de los alumnos, aportando aspectos contemporáneos en la enseñanza de la mecánica clásica. Considerando que la astronomía tiene un potencial motivador para alumnos y profesores, su abordaje es importante en la comprensión de conceptos, promoviendo discusiones sustanciales, consintiendo en el proceso de alfabetización científica en la educación básica.

Palabras clave: Enseñanza de la física; Enseñanza de la astronomía; Enseñanza de las colisiones; Formación planetaria

\section{Introdução}

Sendo necessário fazer uma reflexão a respeito da contextualização do Ensino de Física nos dias atuais, o presente trabalho propõe uma abordagem a partir dos conceitos de Astronomia. Dias e Rita (2008), reconhecem a importância da Astronomia em diversas áreas de conhecimento, pelo fato de possuir características interdisciplinares e motivacionais, as quais proporcionam aos estudantes uma visão ampliada dos fenômenos da natureza. Diante de uma profunda investigação, fez-se necessário fundamentar a importância da contextualização do ensino de colisões através da teoria de formação planetária, evidenciando a seguinte pergunta central: quais as potencialidades do ensino de Colisões no Contexto da Astronomia?

O trabalho Rosa e Dias (2021), aborda o desenvolvimento de conceitos físicos relacionados às colisões mecânicas de forma contextualizada à teoria de formação dos planetas, o que motivou um aprofundamento nas investigações, através da revisão bibliográfica baseada em livros, artigos, monografias, dissertações e teses, os quais abordam a importância da inserção da Astronomia no ensino de Física e a formação planetária através da hipótese nebular de Immanuel Kant (1724 a 1804), o qual afirma que a formação dos planetas ocorreram a partir de blocos de gás e poeira, que se condensaram ao redor da estrela em formação (Tyson, 2015).

O artigo tem como objetivo fundamentar a importância da inserção da Astronomia na educação básica, a fim de contextualizar o Ensino de Física, uma vez que a presente proposta visa possuir como fundamento a Base Nacional Comum Curricular - BNCC (2018) e os Parâmetros Curriculares Nacionais - PCN (2006), que se tratam de diretrizes elaboradas para orientar educadores, através da normatização de algumas características fundamentais inerentes a cada disciplina.

\section{Um Estudo de Colisões a Partir da Teoria de Formação Planetária}

A formação dos planetas ${ }^{1}$ ocorre em regiões do espaço que se ampliam desde o centro do Sistema Solar até distâncias desconhecidas, integradas entre dois planos não muito longínquos (Martioli, 2006). De acordo com a teoria de formação dos planetas, a origem do Sistema Solar se deu através do colapso gravitacional da nebulosa protoestelar ${ }^{2}$, dando origem a formação da estrela na extensão central do disco protoplanetário ${ }^{3}$ em sua volta, constituído de gás e poeira, no qual se dará a formação dos planetas (Oliveira Filho, 2017). De acordo com Saraiva, et al (2021), as partículas em estado sólido estando próximas da protoestrela tendem a vaporizar, em decorrência da alta energia recebida pela partícula. Portanto, as partículas massivas são atraídas para as áreas mais centrais do disco, conforme a Figura 1.

\footnotetext{
${ }^{1}$ Explicações complementares a respeito das formações dos planetesimais poderão ser constatadas em Martioli (2006) \& Pacheco (2020).

${ }^{2}$ Objeto prestes a se tornar uma estrela, caso a sua massa seja suficiente para que tal fenômeno aconteça.

${ }^{3}$ Condensação de matéria que faz parte da fase inicial do processo de evolução de um planeta.
} 
Figura 1 - Teoria de formação dos planetesimais.

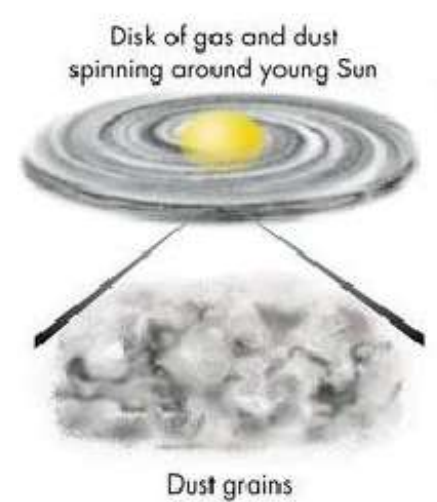

A

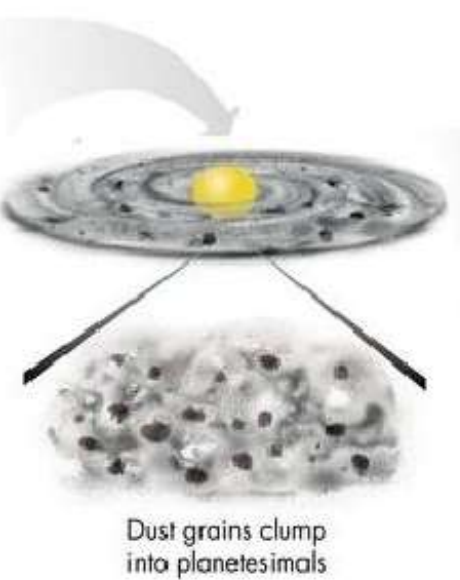

inta planetesimals

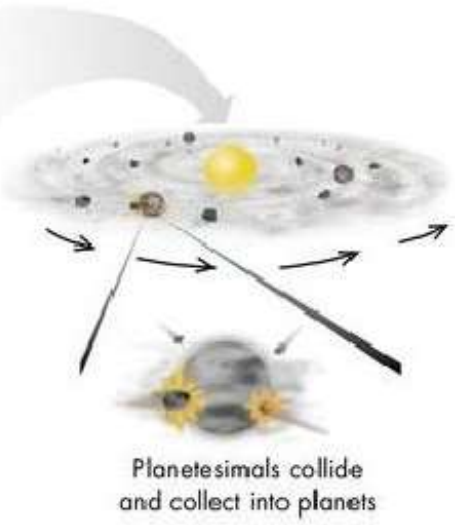

B

Fonte: <https://edisciplinas.usp.br/>.

As poeiras interestelares se concentram no plano central do disco, devido a atração gravitacional. Em decorrência desse fenômeno, as colisões entre as partículas tornam-se frequentes. Sendo assim, a teoria de formação planetária afirma que no decorrer de centenas de milhões de anos, grãos e poeiras interestelares chocam-se uns com os outros constantemente (Martioli, 2006 \& Pacheco, 2020), e consequentemente trocar energia e momento, devido as colisões. Teoricamente, as colisões mecânicas, a energia mecânica e o momento linear total das n partículas envolvidas na colisão se conservam. Sendo assim, a conservação só ocorre se as $n$ partículas envolvidas nessas colisões estiverem isoladas de forças exteriores (Nussenzveig, 2013). Sendo assim, podemos afirmar que:

$$
\begin{gathered}
\Delta E_{\text {mec }}=0 \Rightarrow E_{\text {mec }}-E_{\text {mec }} \Rightarrow E_{\text {mee }}=E_{\text {mec }} \Rightarrow E_{\text {mec }}=\text { constante } \\
\Delta p_{\text {sis }}=0 \Rightarrow P_{\text {sis }}-P_{\text {sis }} \Rightarrow P_{\text {sis }}=P_{\text {si } \varepsilon_{0}} \Rightarrow P_{\text {sis }}=\text { constante }
\end{gathered}
$$

Logo, a conservação do momento linear total é dada por:

$$
\sum_{i=2}^{i=n} m_{i} \times v_{i_{i}}=\sum_{i=2}^{i=n} m_{i} \times v_{i}
$$

Portanto, as colisões entre partículas do disco planetário, podem ser dos tipos elástica ou inelástica (Martioli, 2006 \& Pacheco, 2020). Nas colisões totalmente inelásticas, a energia cinética final do sistema após a colisão $\left(K_{\text {gi̊s }}\right)$ torna-se menor se comparada com a energia cinética antes do choque $\left(K_{\text {ging }}\right)$. Logo,

$$
K_{\text {sis }} \ll K_{\text {sis }} \Rightarrow \frac{1}{2} \cdot v_{\text {sis }}^{2} \cdot \sum_{i=2}^{i=n} m_{i_{0}} \ll \frac{1}{2} \cdot \sum_{i=2}^{i=n} m_{i} \cdot v_{i_{0}}^{2}
$$


Um exemplo de colisão totalmente inelástica abordado nos livros didáticos de Física, é o pêndulo. Um projétil de massa $m$ e velocidade de módulo $v$, que colide com um bloco de madeira de massa $M$ e fica encravado em seu interior. $\mathrm{O}$ pêndulo balístico foi criado em 1742 com o intuito de medir velocidades de projeteis através de colisões inelásticas com um corpo de massa muito maior (Nussenzveig, 2013).

Figura 2 - Pêndulo balístico.

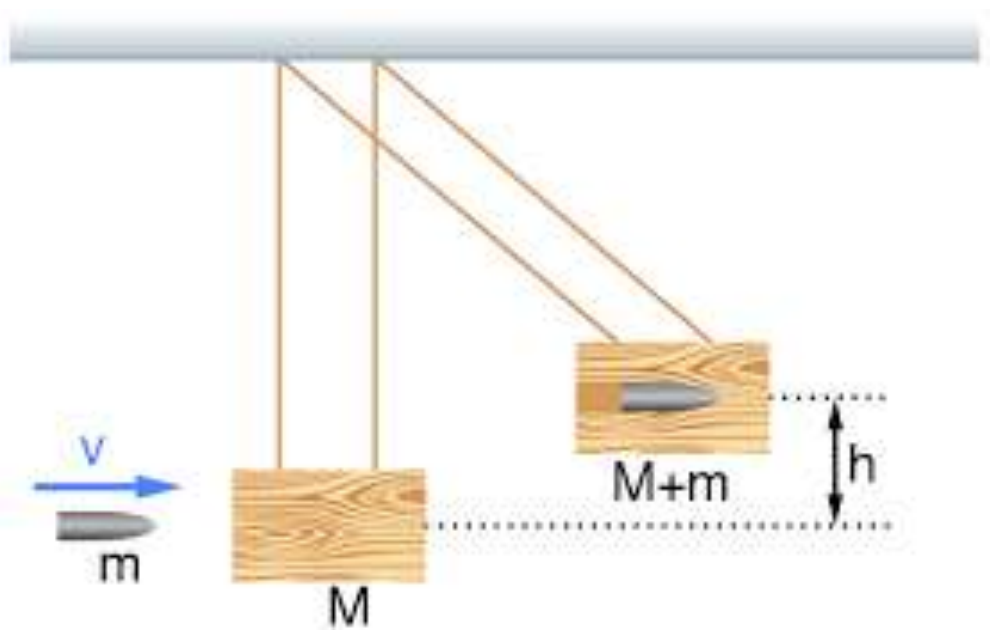

Fonte: 〈https://www.ufrgs.br/amlef/glossario/pendulo-balistico-2/>.

As partículas envolvidas na colisão passam a se movimentar juntas após a interação, formando um só corpo, em que a massa total será a soma das massas das partículas incluídas nessa interação, cuja descrição é explícita na equação (3) e da conservação do momento linear total:

$$
\sum_{i=2}^{i=n} m_{i} \cdot v_{i_{0}}=v_{s i s_{f}} \cdot \sum_{i=2}^{i=n} m_{i} \cdot v_{i}
$$

As características desse tipo de colisão demonstram que quando colidem, os grãos de poeira que estavam distantes, grudam-se uns nos outros, formando um montículo, cujo a dimensão pode chegar até $30 \mathrm{~cm}$. A massa dos montículos aumenta, através da acreção (acumulo de matéria na superfície de um corpo) de partículas que interceptam suas órbitas (Martioli, 2006 \& Pacheco, 2020).

De acordo com Sobrinho (2013), os Asteroides são corpos pequenos rochosos ou metálicos que orbitam o Sol. Embora sejam muito pequenos para serem considerados planetas, os Asteroides também são chamados de planetas secundários, situados na Cintura de Asteroides que fica entre Marte e Júpiter (2.1 U.A - 3.5 U.A). Partindo desse pressuposto, Oliveira (2018) afirma que as colisões envolvendo planetesimais e embriões gera um novo corpo, onde a massa é a soma da massa dos planetas envolvidos e o movimento linear total envolvido é conservado. 
Figura 3 - Formação do Asteroide 2015 TC25.

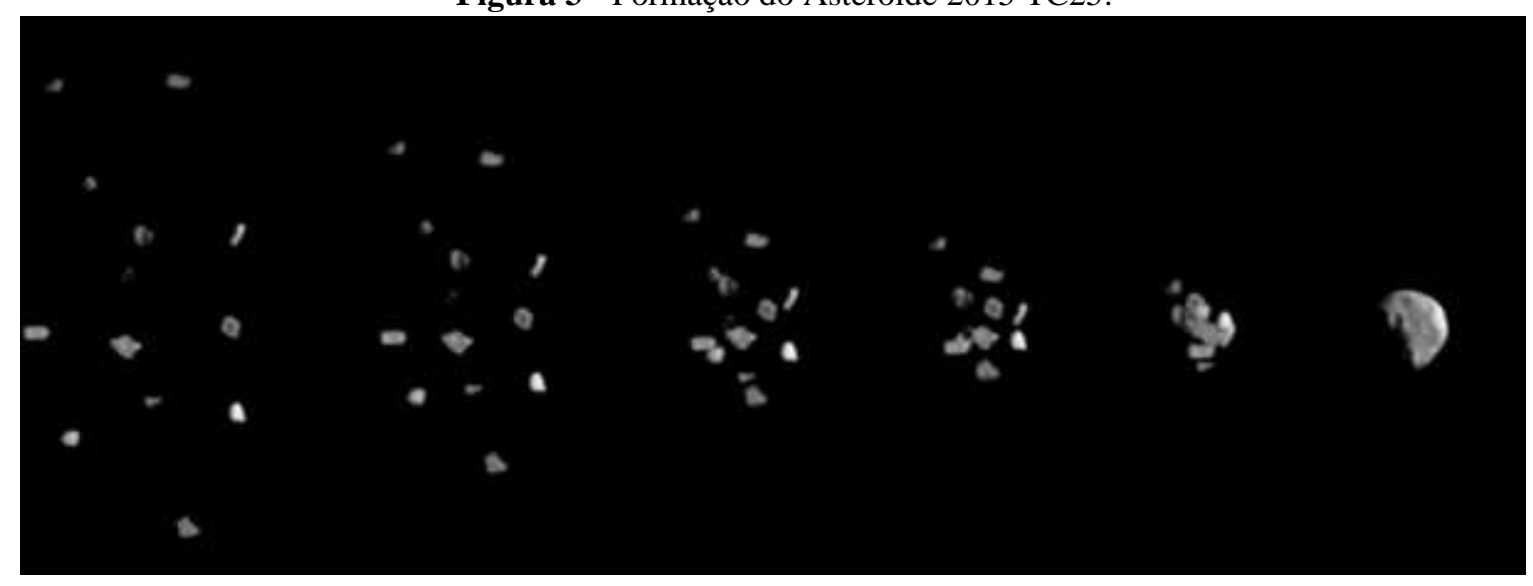

Fonte: <https://www.ccvalg.pt/astronomia/noticias/2016/12/2_2015_tc25.htm>.

Quando as velocidades dos corpos antes da colisão são pequenas, é considerável sua adequação para aglutinação, por adquirirem velocidades inferiores das que possuíam antes da colisão. Nesses casos, as colisões são consideradas completamente inelásticas, a qual o módulo da velocidade final de todo o sistema depois dessa colisão, pode ser calculado isolando $v_{\text {siģ }}$ na equação (4):

$$
v_{s i g_{f}}=\frac{\sum_{i=2}^{i=n} m_{i} \cdot v_{i_{0}}}{\sum_{i=2}^{i=n} m_{i}}
$$

Embora as colisões totalmente inelásticas entre os corpos sejam importantes na explicação da agregação de matéria, não são suficientes para elucidar o processo de evolução de massa a fim de formar corpos maiores, chamados de planetesimais (Martioli, 2006). Os planetesimais, por possuírem massas maiores para darem continuidade ao processo de acúmulo de massa por meio da atração gravitacional, tornam-se planetesimais cada vez maiores, chamados de protoplanetas (Rosa \& Dias 2021).

As colisões entre planetesimais são processos que ainda não são completamente conceituados na teoria de formação dos planetas, visto que não são necessariamente inelásticas. Em outros termos, essas colisões podem ser totalmente elásticas e não haveria aglutinação de matéria (Martioli, 2006 \& Pacheco, 2020).

$$
K_{S I S_{f}}=k_{S I S_{1}} \rightarrow \frac{1}{2} \cdot \sum_{i=2}^{i}=m_{i} \cdot v_{i f}^{2}=\frac{1}{2} \sum_{i=2}^{i=n} m_{i} \cdot v_{i 0}^{2}
$$

A equação (2) descreve a conservação do momento linear total em colisões absolutamente elásticas. Assim sendo, os choques que ocorrem entre as bolas de bilhar são exemplos de colisões totalmente elásticas, em que a energia cinética se conserva e os corpos se separam após o choque. Logo, a colisão entre duas bolas de bilhar trata-se de um evento isolado em que uma força exorbitante age sobre os corpos em um curto intervalo de tempo (Nussenzveig, 2013). 
Figura 4 - Colisão entre bolas de bilhar.

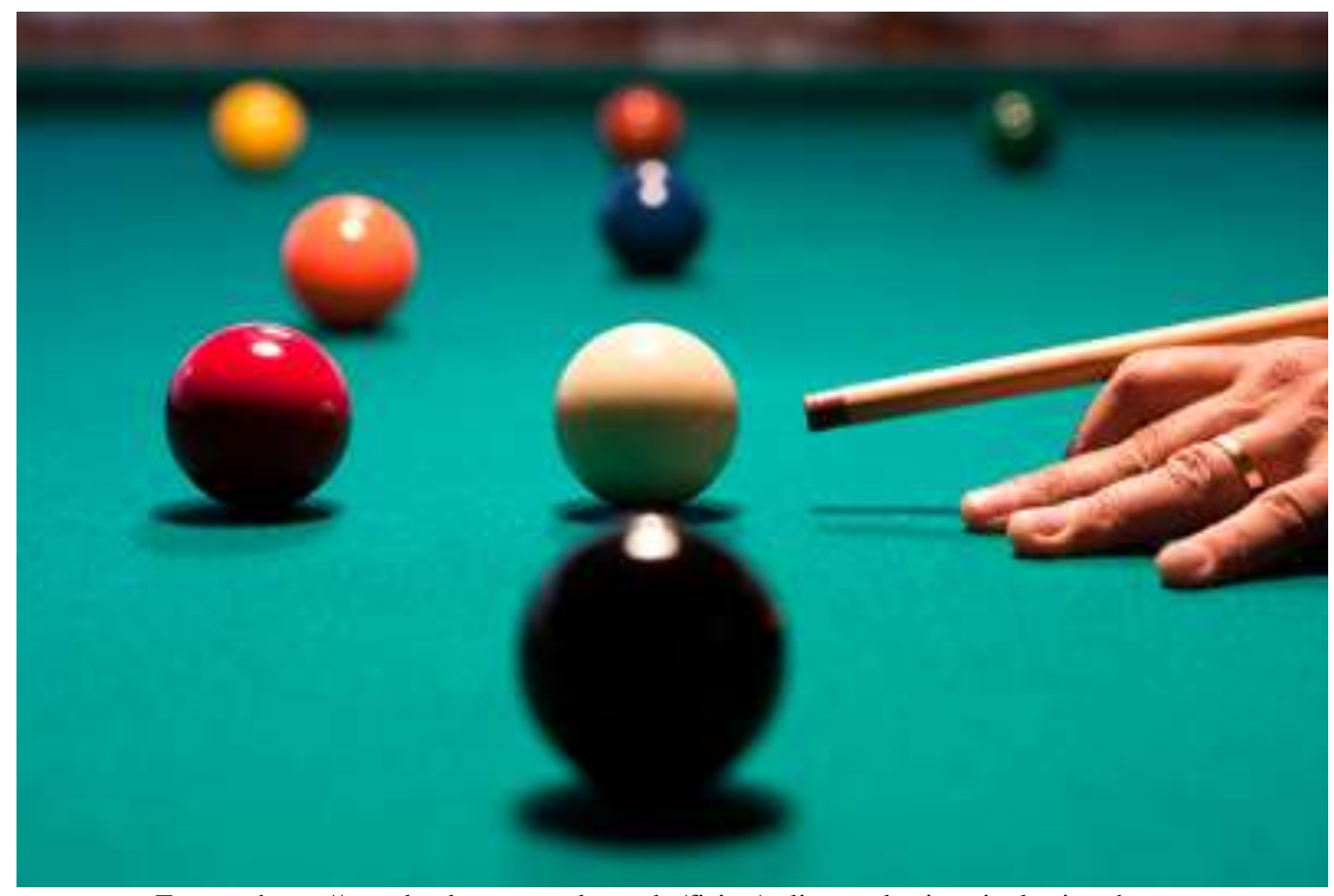

Fonte: <https://mundoeducacao.uol.com.br/fisica/colisoes-elasticas-inelasticas.htm>.

A colisão é um fenômeno isolado no qual a força relativamente intensa comporta-se em cada um dos corpos por um curto intervalo de tempo. Existem três tipos de leis de conservação que reagem às colisões, são elas: momento linear, momento angular e energia (Nussenzveig, 2013).

\section{Metodologia}

O presente trabalho se deu com a formação teórica do tema, motivando uma profunda pesquisa bibliográfica (Boente \& Braga, 2004) e (Thomas et al., 2012). Tendo a pesquisa bibliográfica como base da investigação científica, caracterizada pelas fontes autênticas e concretas, as quais justificaram a investigação, foram feitas buscas em obras já publicadas a fim de estudar o tema a ser investigado, cuja a análise qualitativa resultou na investigação preliminar a respeito do tema da pesquisa (Andrade, 2010), (Gil, 2002) e (Lakatos \& Marconi, 2003).

A sondagem das fontes bibliográficas teve como ponto de partida os trabalhos (artigos, dissertações e teses), os quais foram encontrados através de pesquisas no google academic, em catálogos, editoras, revistas, teses e artigos, periódicos da CAPES, plataforma Sucupira e documentos norteadores da elaboração do currículo do Ensino Médio.

Atendendo aos requisitos desejáveis na Base Nacional Comum Curricular - BNCC (2018) para a área de Ciências da Natureza e suas Tecnologias e os Parâmetros Curriculares Nacionais para o Ensino Médio - PCN (2006), foi realizada uma revisão bibliográfica, a qual possibilitou uma análise considerável, envolvendo a importância dos tópicos de Astronomia na educação básica, dando ênfase a sua importância na contextualização do Ensino de Física e sua utilidade como ferramenta paliativa na educação formal, predispondo a compreensão do estudo de Colisões através da teoria de formação planetária.

\section{Resultados e Discussão}

Diante do cenário contemporâneo, os estudantes não contemplam as potencialidades e similaridades entre os conteúdos de Física, teorias científicas e situações do cotidiano. Sendo assim, os diferentes tipos de fenômenos presentes no cotidiano não são temas tratados na escola e tendem a receber explicações singulares, instigadas por pontos de vista, fábulas e 
várias informações que não se ajustam com a Ciência (Pietrocola, 1999). Além das discrepâncias citadas anteriormente, os trabalhos Porlán e Rivero (1998) apontam os seguintes problemas em relação às técnicas de ensino de professores das Ciências da Natureza:

a) a assimilação minguada de diferentes tipos de conhecimentos (científicos, sociais, pessoais, metadisciplinares ${ }^{4}$ ) na elaboração de conteúdos;

b) o nível de flexibilização do plano de atividades frequentemente detalhado, restrito e inexorável e em outro extremo, pouco detalhado e totalmente distendido;

c) a visão abreviativa da avaliação interpretada como uma mensuração concreta do grau de entendimento acadêmico dos alunos como uma reprodução subjetiva sobre as atitudes e o esforço dos alunos.

Além das limitações no Ensino de Física, é necessário observar que é bastante recorrente que grande parte dos estudantes e professores considere a Física como uma extensão da Matemática, devido as dificuldades em compreender, tornando-a menos atrativa (Gomes et al., 2017).

Sendo assim, a Astronomia é apreciada no Ensino das Ciências, devido a possibilidade de percepção mais ampliada sobre diversos fenômenos da natureza, atraindo o interesse dos estudantes e sendo fundamental na formação cidadã do indivíduo, diante do mundo que o cerca (Rodrigues \& Briccia, 2020). O pensamento dos autores citados anteriormente traz um significado à competência investigativa, o resgate do espírito questionador e o desejo de conhecer o mundo em que se habita, os quais são fundamentais para o Ensino de Física (Brasil, 2006).

A Base Nacional Comum Curricular - BNCC (Brasil, 2018) afirma que a área de Ciências da Natureza e suas Tecnologias deve garantir aos estudantes o desenvolvimento de competências específicas, as quais são:

1. Analisar fenômenos naturais e processos tecnológicos, com base nas relações entre matéria e energia, para propor ações individuais e coletivas que aperfeiçoem processos produtivos, minimizem impactos socioambientais e melhorem as condições de vida em âmbito local, regional e/ou global.

2. Construir e utilizar interpretações sobre a dinâmica da Vida, da Terra e do Cosmos para elaborar argumentos, realizar previsões sobre o funcionamento e a evolução dos seres vivos e do Universo, e fundamentar decisões éticas e responsáveis.

3. Analisar situações-problema e avaliar aplicações do conhecimento científico e tecnológico e suas implicações no mundo, utilizando procedimentos e linguagens próprios das Ciências da Natureza, para propor soluções que considerem demandas locais, regionais e/ou globais, e comunicar suas descobertas e conclusões a públicos variados, em diversos contextos e por meio de diferentes mídias e tecnologias digitais de informação e comunicação - TDIC (Brasil, 2018, p. 539).

As três competências específicas objetivam introduzir a prática da investigação científica e evidenciar a importância dessa abordagem na análise do mundo hodierno. Portanto, evidencia-se a importância do saber científico no Ensino Física, a qual vai além das resoluções de questões que envolvem cálculos. Logo, Assunção e Tenório (2021) afirmam que o saber deve estar acessível ao aluno, onde a linguagem é um fator primordial para o sucesso ou fracasso do plano pedagógico, fundamentando a importância da contextualização do Ensino de Física.

Segundo a Base Nacional Comum Curricular - BNCC (2018) o processo de transformação e evolução fazem parte da natureza e ocorrem das moléculas às estrelas em diferentes intervalos de tempo. A competência específica 2 proporciona ao estudante a oportunidade de organizar questões que identifiquem a humanidade e o planeta Terra na história do Universo.

O interesse em pesquisar sobre o Ensino de Astronomia no Brasil tem crescido de forma significativa nos últimos anos, embora ainda seja exíguo na educação básica (Langhi \& Nardi, 2012) e (Langhi \& Scalvi, 2013). Os conteúdos de Astronomia vêm sendo abordados, mesmo que de forma circunscrita, seja na educação formal ou informal alguns componentes

${ }^{4}$ Proposta metodológica que consiste na construção participativa e criativa do escopo das disciplinas onde é aplicada. 
da Astronomia podem estar presentes nas aulas de Ciências ou de Física (Langhi \& Nardi, 2009), justificando o pensamento de Chevallard (1991), o qual defende que o saber não é inerte, pois está carregado de transformações, sendo notável desde o começo da educação básica, uma vez que:

[...] à medida que se aproxima a conclusão do Ensino Fundamental, os alunos são capazes de estabelecer relações ainda mais profundas entre a ciência, a natureza, a tecnologia e a sociedade, o que significa lançar mão do conhecimento científico e tecnológico para compreender os fenômenos e conhecer o mundo, o ambiente, a dinâmica da natureza (Brasil, 2018, p. 343).

A Astronomia possui um potencial motivador no processo de ensino e aprendizagem, sendo importante na educação formal. A interdisciplinaridade no Ensino de Astronomia, proporciona uma universalidade de caráter minimamente considerável, sendo totalmente dependente das Ciências e das tecnologias atuais. Além disso, a Astronomia é fundamental na motivação dos alunos e aprofundar conhecimentos em diversas áreas (Langhi \& Nardi, 2013).

Partindo do ponto de vista dos trabalhos investigados na revisão de bibliográfica, a contextualização do Ensino de Física é primordial, a fim de atender as necessidades da educação básica dos discentes, a qual é considerada como uma das soluções para as limitações na contextualização dos conteúdos. A contextualização no ensino das Ciências possui uma contribuição satisfatória na formação do cidadão crítico, desenvolvendo competências investigativas que contribuem com os aspectos culturais, cognitivos e sociais, os quais são fundamentais para interpretar o mundo no qual estamos inseridos. O desenvolvimento do pensamento crítico do indivíduo é resultado de uma aprendizagem baseada em vivências, as quais as condições de vida humana dependem direta e indiretamente. O Ensino de Física deve contribuir com a vida social dos educandos através da relação entre os fenômenos do cotidiano e os saberes formais, democratizando o conhecimento e a desenvoltura de novas competências (Brasil, 2006).

\section{Conclusão}

Diante de uma revisão bibliográfica eminentemente substancial a respeito do Ensino de Colisões e as contribuições do ensino de Física no contexto da Astronomia, foi possível incrementar o pensamento dos autores em relação às reais possibilidade de contextualização dos fenômenos da natureza no ensino formal. As orientações curriculares para o Ensino de Física, proporcionam um modelo de ensino contextualizado, de acordo com as vivências dos estudantes, a fim de formar um cidadão crítico e alfabetizado cientificamente.

A contextualização do ensino de colisões através da teoria de formação planetária, possibilitou a compreensão da origem do Sistema Solar, abordando conceitos pontuais de Astronomia no ensino de Física. A compreensão destes aspectos científicos proporciona a desenvoltura de uma educação científica que contribui com a vida social e cultural dos educandos, sendo primordial na compreensão do mundo em que estão inseridos. Além disso, as competências específicas da área de Ciências da Natureza e suas Tecnologias incentivam a prática da investigação científica, evidenciando a importância dessa abordagem no cotidiano dos estudantes.

\section{Referências}

Andrade, M. M. (2010). Introdução à metodologia do trabalho científico: elaboração de trabalhos na graduação. Ed. Atlas.

Assunção, T. V. \& Tenório, A. C. (2021). Possíveis aproximações entre o grau de alfabetização científica de alunos do Ensino Médio e a prática pedagógica do professor de Física. Revista de Ensino de Ciências e Matemática, 12 (1), 1-25.

Boente, A. \& Braga, G. (2004). Metodologia científica contemporânea para universitários e pesquisadores. Brasport, 79-98.

Borragini, E. F. et al. (2013). Ensino de astronomia: cenários da prática docente no ensino fundamental. UFSCar.

Brasil. Ministério da Educação (MEC). (2018). Base Nacional Comum Curricular. 
Brasil. Ministério da Educação (MEC). (2006). Parâmetros curriculares nacionais: Ensino Médio. Parte III - Ciências da Natureza, Matemática e suas tecnologias, Brasília DF.

Chevallard, Y. (1991). La transposición didática: de saber sabio al saber ensinado. Tradución. Claudia Gilman. Auque Grupo editor S.A.

Dias, C. A. C. M., Santa Rita \& Josué R. (2008). Inserção da Astronomia como Disciplina Curricular do Ensino Médio. Revista Latino-Americana de Educação em Astronomia, São Carlos (SP), (6), 55-65.

Gil, A. C. (2002). Como elaborar projetos de pesquisa. Ed. Atlas.

Gomes, E. C., Batista, M. C. \& Fusinato, P. A. (2017). O Estudo Das Ondas Eletromagnéticas a Partir Do Enfoque Cts: Uma Possibilidade Para O Ensino De Física No Ensino Médio. Revista de Ensino de Ciências e Matemática, 8 (1),109-125.

Kantor, C. A. (2001). A ciência do céu: uma proposta para o ensino médio. Dissertação (Mestrado) - Departamento de Física Experimental, Instituto de Física, Universidade de São Paulo, São Paulo.

Lakatos, E. M. \& Marconi, M. A. (2003). Fundamentos de Metodologia Científica. Ed. Atlas.

Langhi, R. (2004). Um estudo exploratório para a inserção da Astronomia na formação de professores dos anos iniciais do Ensino Fundamental. Dissertação (Mestrado em Educação para a Ciência) - Faculdade de Ciências, UNESP, Bauru.

Langhi, R. (2009). Astronomia nos anos iniciais do ensino fundamental: repensando a formação de professores. Tese (Doutorado em Educação para a Ciência) - Faculdade de Ciências, UNESP, Bauru.

Langhi, R. \& Scalvi, R.M.F. (2013). Aproximações entre as comunidades científica, amadora e escolar: estudando as potencialidades de observatórios astronômicos para a educação em astronomia. Revista Instrumento de Estudos e Pesquisas em Educação, 15 (1), 25-38.

Langhi, R. \& Nardi, R. (2013). Educação em Astronomia: repensando a formação de professores. Escrituras Editora.

Langhi, R. \& Nardi, R. (2009). Ensino da astronomia no Brasil: educação formal, informal, não formal e divulgação científica. Revista Brasileira de Ensino de Física, 31 (4), 4402.

Marconi, M. A. \& Lakatos, E. M. (2013). Fundamentos de Metodologia Científica. Ed. Atlas S.A.

Martioli, E. (2006). Exoplanetas: O que são e como detectá-los. Dissertação de Mestrado, Instituto Nacional de Pesquisas Espaciais (INPE). São José dos Campos, São Paulo.

Nussenzveig, H. M. (2013). Curso de Física Básica 1: Mecânica. Ed. Blucher.

O. F., Kepler de Souza \& Saraiva, M. F. O. (2017). Astronomia \&Astrofísica. Ed. Livraria da Física.

Oliveira, P. F. (2018). Formação de Planetas terrestres: o caso de acreções ineficientes. Dissertação de Mestrado, Faculdade de Engenharia, Universidade Estadual Paulista. Guaratinguetá, São Paulo.

Pacheco, J. A. F. (2020). Vida no Universo. Ed. EDUSP.

Pietrocola, M. (1999). Construção e realidade: o realismo científico de Mário Bunge e o ensino de ciências através de modelos. Investigações em Ensino de Ciências, Florianópolis, 4 (3), 213-227.

Porlán, R. \& Rivero, A. (1998). El conocimiento de los professores - Uma propuesta formativa en el área de ciencias. Diada Editora.

Rodrigues, F. M. \& Briccia, V. (2020). O Ensino De Astronomia E As Possíveis Relações Com O Processo De Alfabetização Científica. Revista LatinoAmericana de Educação em Astronomia, (28), 95-111.

Rosa, N. L. \& Dias, Bruno Leonardo do Nascimento. (2021). Potencialidades dos Conceitos de Formação Planetária como Abordagem Interdisciplinar do Ensino de Colisões nos Cursos de Graduação em Física. Simpósio Nacional de Ensino de Física, Santo André (SP).

Saraiva, M. F. O. et al. (2001). Universidade Federal do Rio Grande do Sul - Instituto de Física. Aula 9: Sistema Solar - Propriedades Físicas dos Planetas.

Sobrinho, J. L. G. Planetas anões, asteroides e cometas. Portugal: Centro de Ciências Exactas e da Engenharia, Universidade da Madeira.

Thomas, A. et al. (2012). A Versatile Method for Cell-Specific Profiling of Translated mRNAs in Drosophila. PLoS ONE 7(7): e40276.

Tyson, N. G. \& Golsmith, D. (2015). Origens. Ed. Planeta do Brasil. 